\title{
Mosquitos (Diptera: Culicidae) en el caserío de Chingalé, Santander, donde se registró un caso humano de encefalitis equina venezolana
}

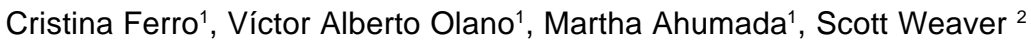 \\ ${ }^{1}$ Laboratorio de Entomología, Instituto Nacional de Salud, Bogotá, Colombia \\ 2 Department of Pathology and Center for Tropical Diseases, University of Texas Medical Branch, Galveston, \\ TX, USA
}

Introducción. El foco enzoótico del subtipo ID del virus de la encefalitis equina venezolana en la región del Magdalena Medio produce esporádicamente casos en humanos. El registro de un caso en una niña de tres años en el caserío de Chingalé, municipio de Puerto Wilches, Santander, motivó este estudio.

Objetivo. Evaluar el caserío de Chingalé como probable sitio de infección.

Materiales y métodos. En junio de 2005 se recolectaron mosquitos con trampas de luz CDC dentro y fuera de las casas; también se colocaron trampas Trinidad y hámster centinela alrededor de las viviendas.

Resultados. En 107 muestreos se recolectaron 14.423 mosquitos distribuidos en 35 especies. La abundancia relativa de los posibles vectores del subtipo ID del virus de la encefalitis equina venezolana encontrados, Culex (Melanoconion) pedroi y $\mathrm{Cx}$. (Mel) ocossa, en general, fue baja $(<4 \%)$. Estas dos especies fueron más frecuentes en el exterior de las viviendas que en los dormitorios: $C x$. ocossa en las trampas CDC y $C x$. pedroi en las Trinidad. $C$. ocossa fue más frecuente en las viviendas. Además, este estudio detectó Psorophora confinis, considerado posible vector de subtipos epidemo/epizoóticos y una alta frecuencia de Mansonia indubitans en las viviendas. Los hámster expuestos no se infectaron.

Conclusiones. La niña pudo infectarse en su casa o cerca de ella, aunque el ciclo epidemiológico del virus no tiene lugar en el casco urbano de Chingalé. Posiblemente ocurre en un lugar cercano y Culex (Melanoconion) infectados llevan el virus al caserío, en donde algunos mosquitos incursionaron a alimentarse.

Palabras clave: virus de la encefalitis equina venezolana, encefalitis por arbovirus, Culex, Colombia.

Mosquitos (Diptera: Culicidae) in the small village where a human case of Venezuelan equine encephalitis was recorded

Introduction. The enzootic focus of subtype ID of Venezuelan equine encephalitis (VEE) virus in the Central Magdalena region (central Colombia) occasionally produces human cases. The report of a VEE infection in a three-year-old girl in the small village of Chingalé, municipality of Puerto Wilches, Santander, motivated this study.

Objective. The village of Chingalé was evaluated as the probable site of infection.

Materials and methods. In June 2005, mosquitoes were collected with CDC light traps in and outside of dwellings in the village. Trinidad traps were placed in nearby vegetation, and hamsters were used as sentinel animals near homes.

Results. One hundred and seven samples, consisting of 14,423 mosquitoes of 35 species were collected. The relative abundance of incriminated vectors of subtype ID of VEE, Culex (Melanoconion) pedroi and $C x$. (Mel.) ocossa, was generally low $(<4 \%)$, but both species were more frequent outside of dwellings than indoors. Cx. (Mel.) ocossa was collected in CDC traps and was more frequent indoors, whereas $C x$. (Mel.) pedroi was found in the Trinidad traps. In addition, Psorophora confinnis was present, recognized as a potential vector of the epidemo/ epizootic subtype. Mansonia indubitans, another recognized vector, was present at high 
frequency within dwellings. The exposed hamsters did not become infected.

Conclusion. The child may have been infected in or near her home, although the epidemiologic cycle of the virus was not demonstrated within the village of Chingalé. Possibly, infected Culex mosquitoes of the subgenus Melanoconion carried the virus into the village from a neighboring habitat.

Key words: Encephalitis virus, Venezuelan equine; encephalitis, arbovirus; Culex, Colombia.

Los casos humanos de encefalitis equina venezolana son ocasionados por diferentes subtipos de una especie de virus llamada VEEV (Togaviridae: Alphavirus), la cual, conjuntamente con otras seis especies de virus, hace parte del complejo serológico de la encefalitis equina venezolana $(1,2)$.

Durante las epidemias en el siglo pasado hasta 1993, solamente se aislaron los subtipos epidemo/ epizoóticos IAB y IC, los cuales a partir de 1938, cuando el virus fue aislado por primera vez, causaron muchas epidemias en el Nuevo Mundo que se extendieron rápidamente y afectaron a miles de équidos y humanos $(3,4)$, debido a que estos subtipos epizoóticos en los caballos desarrollan viremias muy altas e infectan muy eficientemente a los mosquitos vectores (5).

Los subtipos enzoóticos comenzaron a aislarse en los años 50 en hábitats selváticos y pantanosos de Suramérica, México y Florida, donde sus ciclos epidemiológicos se mantienen permanentemente $(1,4)$. A diferencia de los subtipos epizoóticos, infectan principalmente pequeños mamíferos, no están asociadas con enfermedad en équidos, pero sí con los humanos, que se pueden infectar y desarrollar la enfermedad, la cual en algunos casos puede llegar a ser fatal (6).

En su ciclo epidémico, tanto los subtipos enzoóticos como los epizoóticos utilizan mosquitos vectores para ser transmitidos a un nuevo hospedero. Las variantes epizoóticas son oportunistas en la utilización de mosquitos mamófilos para su transmisión, entre los cuales Aedes (Ochlerotatus) taeniorhynchus (Wiedemann, 1821) y Psorophora (Grabhamia) confinnis (Lynch Arribalzaga, 1891)

\footnotetext{
Correspondencia:

Cristina Ferro, Instituto Nacional de Salud, Avenida Calle 26 № 51-20, Bogotá, D.C., Colombia.

Teléfono: 220 7700; fax: 2200923.

crisferro@yahoo.com

Recibido: 08/08/07; aceptado:26/12/07
}

han sido las especies más comprometidas. En cambio, para las variantes enzoóticas, los únicos vectores incriminados son mosquitos de la sección Spissipes del subgénero Culex Melanoconion (1): Cx. (Mel.) portesi (Sevenet and Abonnenc, 1941) del virus Mucambo (subtipo IIIA) en Trinidad, $C x$. (Mel.) aikenni (Aiken and Rowland,1906) (sensu lato ocossa Dyar and Knab, 1919 y panocossa Dyar,1923) del subtipo ID en Panamá, Cx. (Mel.) cedecei (Stone and Hair,1968) del virus Everglades (subtipo II) en el sur de Florida, Cx. (Mel.) taeniopus (Dyar and Knab, 1907) del subtipo IE en Guatemala y en Colombia Cx. (Mel.) vomerifer (Komp,1932), Cx. (Mel.) pedroi (Sirivanakarn and Belkin,1980) y Cx. (Mel.) adamesi Sirivanakarn and Galindo,1980) del subtipo ID (7).

Por medio de los estudios genéticos se ha demostrado que las cepas epizoóticas han emergido a partir de un linaje enzoótico; el subtipo IC en dos ocasiones independientes a partir del subtipo ID, por sustituciones en los aminoácidos de la glicoproteína E2 de la cubierta del virus $(8,9)$. Además de esto, en la epidemia de México (19931996), la cual se presentó en una área completamente deforestada en los estados de Chiapas y Oaxaca, se aisló una variante epizoótica del subtipo IE del cerebro y el suero de caballos enfermos (10); antes de 1993 no se sabía que los subtipos enzoóticos tenían potencial epizoótico por sí mismos (11). Los mecanismos de emergencia utilizados por el subtipo IE fueron similares a los que ocurren en el subtipo ID; pero en este caso, la sustitución de un solo aminoácido en la glicoproteina E2 de la cubierta, le permitieron al subtipo IE, en ausencia de su vector enzoótico natural Cx. (Mel.) taeniopus, cambiar de mosquito vector y utilizar a Aedes (Ochlerotatus) taeniorhynchus, que era la especie más abundante en la región durante el brote.

En Colombia, de los subtipos enzoóticos únicamente se ha aislado el ID, en las siguientes 
localidades: Tibú (Norte de Santander), Tumaco (Nariño) y el valle del Magdalena Medio (12-14). En esta última región, los estudios longitudinales realizados en los bosques por tres décadas demostraron la circulación permanente del virus $(14,15)$. Los mosquitos Cx. (Mel.) pedroi y $C x$. (Mel.) vomeriferfueron incriminados como vectores enzoóticos primarios, por su capacidad de transmitir el virus y su gran abundancia, y $C x$. (Mel.) adamesi fue considerado un vector secundario (7).

Se han registrado casos de encefalitis equina venezolana en humanos en el área rural desde 1961, algunos de éstos confirmados con aislamiento del virus $(16,17)$. Los primeros registros en la vecindad a las ciudades se dieron en el 2001, año en el cual se registraron tres casos en el área periurbana de Barrancabermeja (Ferro C, Ramírez M, González M, Ahumada ML, Boshell J. Ciclo de transmisión enzoótica del subtipo ID del virus de la encefalitis equina venezolana en la periferia de la ciudad de Barrancabermeja, valle medio del río Magdalena. Biomédica 2003;23 (Supl.1):125) y en el 2005 se diagnosticó un caso en una niña de tres años, la cual según su madre no había salido del casco urbano del corregimiento de Chingalé, municipio Puerto Wilches.

En relación con las actividades de vigilancia entomológica, hay información del área periurbana de Barrancabermeja, donde también se registró la presencia de los vectores $C x$. (Mel.) adamesi, Cx. (Mel.) pedroi y Cx. (Mel.) vomerifer, pero a diferencia de los hallazgos realizados en el bosque, $C x$. adamesise registra con una abundancia relativa mucho mayor (Ferro C, Ramírez M, González M, Ahumada ML, Boshell J. Ciclo de transmisión enzoótica del subtipo ID del virus de la encefalitis equina venezolana en la periferia de la ciudad de Barrancabermeja, valle medio del río Magdalena. Biomédica 2003;23 (Supl.1):125).

Para Chingalé, de donde no existen registros de especies de mosquitos vectores de encefalitis equina venezolana, se plantea que, por lo menos, una de estas tres especies podría estar llegando hasta el domicilio en el casco urbano.

Aunque el subtipo ID del VEEV que circula en el Magdalena medio es avirulento para équidos y todavía no ha mostrado su potencial epizoótico por sí mismo, dada la importancia del registro de Chingalé, se realizó una investigación preliminar de campo, en la cual se hizo una búsqueda activa de casos febriles en humanos y la vacunación de los équidos.

Como resultado, en ese estudio se encontraron ocho casos febriles en los 297 residentes valorados y se vacunó el $86 \%(70 / 81)$ de los équidos (Vera N, Villamizar MC, Sanchez LR, Jaimes LS, Rodríguez JP. Informe preliminar estudio de brote de encefalitis equina venezolana, corregimiento de Chingalé, municipio de Puerto Wilches, departamento de Santander. Instituto Nacional de Salud. Secretaría de Salud de Santander. Mayo de 2005).

El suero de uno de los pacientes febriles, correspondiente al vecino de la casa habitada por la niña, presentó una lgM alta, lo cual confirma la circulación reciente del virus en el área. Ante la falta de información de las especies de mosquitos probables vectores del VEEV en el caserío, se recomendó desarrollar el presente estudio entomológico, con el objeto de evaluar el caserío de Chingalé como probable sitio de infección del subtipo ID del virus de la encefalitis equina venezolana mediante la búsqueda de mosquitos posibles vectores del virus en el casco urbano del corregimiento de Chingalé.

\section{Materiales y métodos}

\section{Área de estudio}

El estudio se realizó del 13 al 18 de junio de 2005, al final de la estación lluviosa, en el caserío de Chingalé $\left(7,68474^{\circ} \mathrm{N}, 73,80297^{\circ} \mathrm{O}\right)$ localizado al noreste de Barrancabermeja a una altitud de 50 metros sobre el nivel del mar y dos metros por debajo de la cota del río Magdalena.

Esta última característica condiciona la formación de caños, lagunas y ciénagas originadas por las aguas del río Magdalena durante la temporada de lluvias, la cual, teniendo en cuenta que la región está sometida a un régimen bimodal de lluvias, se registra dos veces en el año.

La temperatura promedio es de $30^{\circ} \mathrm{C}$ y la humedad relativa de $80 \%$. La deforestación, al igual que en la mayor parte del valle del río Magdalena medio, 
ha sido muy alta, cambiando en gran parte la vegetación original del bosque a una de tipo arbusto mezclada con cultivos.

Según el censo realizado en el 2004, la localidad contaba con 68 viviendas y una población de 346 habitantes (Vera N, Villamizar MC, Sánchez LR, Jaimes LS, Rodríguez JP. Informe preliminar estudio de brote de encefalitis equina venezolana, corregimiento de Chingalé, municipio de Puerto Wilches, departamento de Santander. Instituto Nacional de Salud. Secretaría de Salud de Santander. Mayo de 2005).

La población en general tiene bajos ingresos; sus actividades económicas principales las constituyen la ganadería y la pesca artesanal, y los cultivos de plátano y cacao. El caserío cuenta con energía eléctrica pero carece de servicios públicos como agua potable y alcantarillado; esta última situación convierte a los caños que circundan las casas en el depósito de todo tipo de basura, tanto de origen humano como de desechos plásticos. El acceso al sitio es fluvial y controlado por los grupos armados; el desplazamiento dentro y fuera del caserío también está controlado.

\section{Muestreo de mosquitos}

Teniendo en cuenta que la menor afectada no había salido del casco urbano del corregimiento, se diseñó un estudio para identificar especialmente las especies de mosquitos que llegaban a las viviendas de los residentes del caserío. En el intradomicilio, la presencia y abundancia de las especies de mosquitos se determinó mediante el uso de trampas de luz CDC activadas de las 18:00 a las 06:00 horas. La unidad de muestreo fue la vivienda y se incluyeron todas las casas que estaban habitadas en el momento de la visita. Se colocó una trampa por vivienda en uno de los dormitorios por una noche, con excepción de la casa de la niña y la de su vecino en donde se hizo muestreo por dos noches.

En el extradomicilio, los muestreos se realizaron con trampa de luz CDC y trampa Trinidad № 17 (TT-17). Esta última trampa está cebada con un animal (roedor) y fue desarrollada para recolectar mosquitos vivos que son atraídos por estos animales; es una adaptación, mucho más pequeña y liviana que la TT № 10 modificada (7), la cual fue diseñada para colocar dos animales o hielo seco como atrayente (18-20). Las trampas se instalaron entre la vegetación que rodea el casco urbano, a una altura de $1,5 \mathrm{~m}$ del nivel del suelo, en una franja virtual de $2 \mathrm{~km}$ de largo por $500 \mathrm{~m}$ de ancho, paralela al caserío.

Simultáneamente, con las trampas del intradomicilio, las CDC se activaron por tres noches seguidas y las trampas Trinidad se dejaron en forma permanente por tres noches y cuatro días. La distancia mínima entre las CDC fue de $100 \mathrm{~m}$ y entre las Trinidad fue de $30 \mathrm{~m}$.

Diariamente en las horas de la mañana, entre las 06:00 y las 07:00, los mosquitos que entraron a las trampas Trinidad, se sacaron con una aspirador manual sin mover las trampas del sitio donde estaban ubicadas; mientras que de las CDC, se recogieron las mallas con los insectos y se separaron los mosquitos de los otros insectos que entraron a la trampa, para su posterior identificación hasta especie. El material recolectado en las trampas CDC se preservó seco en cajitas entomológicas preparadas previamente con varias capitas de papel muy fino y silica gel en el fondo; los mosquitos de las trampas Trinidad se colocaron en nitrógeno líquido para intentar el aislamiento del virus en caso de que los hámster que se colocaron como cebos en las trampas se infectaran con el VEEV. Terminado el trabajo de campo, los hámster se mantuvieron en observación por dos semanas más.

Como complemento a los muestreos con las trampas CDC y TT-17, durante el día y aproximadamente por 15 minutos, en algunas viviendas y con ayuda de una linterna, un mariposero y un aspirador manual, se recolectaron mosquitos que estuvieran en el interior de los dormitorios, reposando en las paredes y sobre la ropa seca colgada o volando. Además, se buscaron formas inmaduras de estos dípteros en criaderos naturales y artificiales. Se inspeccionó una laguna, los caños del río Magdalena que bordean el caserío, charcas en los solares de las viviendas, tanques bajos para almacenamiento de agua y todo tipo de recipiente que pudiera acumular agua. El material recolectado se preservó en alcohol al 70\%. 
Los mosquitos y las formas inmaduras capturados se identificaron siguiendo varias claves dicotómicas (21-25).

\section{Materiales empleados para la construcción de las viviendas, uso de toldillos e insecticidas}

Se realizó una inspección ocular en todas las viviendas incluidas en el muestreo y se registró el tipo de material empleado en la construcción de las mismas, con el fin de determinar si esta variable afectaba la abundancia intradomiciliaria de los mosquitos recolectados en las trampas CDC. Además, en cada vivienda se hicieron tres preguntas al jefe del hogar o al adulto responsable de la casa: 1) número de personas que normalmente dormían en la vivienda;2) número de toldillos utilizados, y 3) uso de insecticidas comerciales.

\section{Análisis de datos}

Se registró el valor de la abundancia media y la desviación estándar para las hembras de todas las especies de mosquitos en el interior y el exterior de las viviendas, tanto para las recolecciones de la trampa CDC como de la Trinidad. Evenness (homogeneidad) de las especies de mosquitos, la diversidad de especies y su varianza, se calcularon utilizando los índices descritos por Bulla (26).

El porcentaje de infestación de las viviendas se calculó para la especie dominante y para las especies con importancia epidemiológica en la transmisión del VEEV recolectadas en las trampas CDC.

Para evaluar si el material en el que estaba construida la vivienda tenía alguna influencia en la abundancia de los mosquitos, se tuvo en cuenta el número total de mosquitos (todas las especies) capturados en la trampa CDC. La abundancia de las especies se presenta como promedios aritméticos hembras por trampa CDC por noche con sus intervalos de confianza al $95 \%$.

Los machos recolectados no se tuvieron en cuenta en el análisis de resultados.

\section{Aspectos éticos}

En esta investigación no se manipularon muestras biológicas de origen humano. Los hámster utilizados en el estudio se manejaron siguiendo las normas técnicas para el manejo de animales.
El presente estudio hace parte del proyecto "Estudio genético de los virus enzoóticos de encefalitis equina venezolana de Colombia para establecer los mecanismos de emergencia epizoodémica periódica", aprobado por los Comités de Investigación y Ética del Instituto Nacional de Salud. La visita a las viviendas se realizó con consentimiento de cada familia.

\section{Resultados}

Se identificaron 35 especies en las 107 muestras tomadas, en las cuales se recolectaron 14.423 mosquitos (14.289 hembras y 134 machos). Todos los machos se capturaron en las trampas CDC. La distribución de las especies por género se registró en la siguiente forma: Aedeomyia, 1; Aedes, 4; Anopheles, 6; Culex, 15; Coquillettidia, 1; Johnbelkinia, 1; Mansonia, 1; Psorophora, 3, y Uranotaenia, 3. La mayor riqueza de especies se presentó en el intradomicilio-CDC, donde se registraron 34 de las 35 identificadas, el extradomicilio-CDC y TT-17 registraron 22 y 17 especies, respectivamente; sin embargo, el índice de evenness fue menor que el extradomicilio-CDC y TT-17. La diversidad de especies (homogeneidad por riqueza de especies) en el intradomicilio-CDC fue menor que en el extradomicilio-CDC y mayor que en el extradomicilio-TT-17 (cuadro 1). Este último resultado se explica por la alta dominancia numérica de Ma. indubitans (Dyar and Shannon, 1925) en el intradomicilio-CDC, 7.193 mosquitos hembra de 9.225 recolectadas respecto al extradomicilio-CDC con sólo 493 Ma. indubitans de 3.778 (cuadro 1).

Del subgénero Melanoconion, serie Spissipes, se encontraron cuatro especies: $C x$. pedroi, $C x$. occosa, Cx. spissipes (Theobald, 1903) y $C x$. crybda (Dyar, 1924); en general, la abundancia media de estas especies fue baja (cuadro 1). $C x$. pedroi y $C x$. ocossa fueron los más frecuentes, con mayor abundancia en el exterior de las viviendas que en los dormitorios. En el extradomicilio-CDC, las trampas CDC fueron más productivas para la especie $C$. ocossa y el extradomicilio-TT17 para Cx. pedroi. Cx. ocossa fue más frecuente en las viviendas que $C x$. pedroi (cuadro 1). De la serie Melanoconion se identificaron cinco especies, Cx. dunni, Cx. ferreri, 
Cuadro 1. Abundancia media, riqueza de especies e índices de homogeneidad y diversidad de los mosquitos recolectados en los dormitorios de las viviendas y en los alrededores, en el caserío de Chingalé, municipio de Barrancabermeja, departamento de Santander.

\begin{tabular}{|c|c|c|c|c|c|c|c|}
\hline Sitio & Intradomicilio & & & Extrad & mic & & \\
\hline Especies de Método & CDC & & CDC & & & TT-17 & \\
\hline mosquitos & $\begin{array}{c}\text { Abundancia } \\
\text { media }^{a}\end{array}$ & $\pm \mathrm{DE}$ & $\begin{array}{c}\text { Abundacia } \\
\text { media }^{\text {a }}\end{array}$ & $\pm \mathrm{DE}$ & $\mathbf{n}$ & $\begin{array}{l}\text { Abundancia } \\
\text { media }^{b}\end{array}$ & $\pm \mathrm{DE}$ \\
\hline & 53 & & 33 & & 18 & & \\
\hline Ad. (Ady.) squamipennis & 0,57 & 1,78 & 2,36 & 3,78 & & 0,56 & 0,24 \\
\hline Ae. (Oc.) angustivittatus & 0,04 & 0,23 & 0,10 & 0,29 & & 0,56 & 0,24 \\
\hline Ae. (Oc.) fulvus & 0,00 & 0,00 & 0,00 & 0,00 & & 0,45 & 0,62 \\
\hline Ae. (Oc.) scapularis & 0,02 & 0,14 & 0,00 & 0,00 & & 0,00 & 0,00 \\
\hline Ae. (Oc.) serratus & 0,04 & 2,27 & 2,27 & 0,67 & & 5,39 & 10,74 \\
\hline An. (An.) punctimacula & 0,74 & 1,43 & 2,50 & 3,47 & & 0,56 & 0,24 \\
\hline An. (Nys.) darlingi & 0,06 & 0,23 & 0,00 & 0,00 & & 0,00 & 0,00 \\
\hline An. (Nys.) braziliensis & 0,04 & 0,19 & 0,06 & 0,25 & & 0,00 & 0,00 \\
\hline An. (Nys.) oswaldoi & 0,07 & 0,26 & 0,03 & 0,17 & & 0,00 & 0,00 \\
\hline An. (Nys.) triannulatus & 0,39 & 0,76 & 0,91 & 2,11 & & 0,00 & 0,00 \\
\hline An. (Nys) spp & 0,26 & 0,52 & 0,27 & 0,45 & & 0,56 & 0,24 \\
\hline An. (Ano.) neumaculipalpus & 0,02 & 0,14 & 0,00 & 0,00 & & 0,00 & 0,00 \\
\hline Cx. (Aed.) amazonensis & 0,02 & 0,14 & 0,00 & 0,00 & & 0,00 & 0,00 \\
\hline Cx. (Aed) spp & 0,30 & 1,46 & 0,06 & 0,24 & & 0,00 & 0,00 \\
\hline Cx. (Cux.) bonneae & 0,02 & 0,14 & 0,00 & 0,00 & & 0,00 & 0,00 \\
\hline Cx. (Cux.) corniger & 0,02 & 0,14 & 0,00 & 0,00 & & 0,00 & 0,00 \\
\hline Cx. (Cux.) nigripalpus & 0,09 & 0,56 & 0,00 & 0,00 & & 0,00 & 0,00 \\
\hline Cx. (Cux.) quinquefasciatus & 0,02 & 0,14 & 0,00 & 0,00 & & 0,00 & 0,00 \\
\hline Culex (Cux) spp. & 5,85 & 7,35 & 11,34 & 7,62 & & 11,28 & 12,36 \\
\hline Culex (Mel.) crybda & 0,04 & 0,27 & 0,00 & 0,00 & & 0,06 & 0,23 \\
\hline Cx. (Mel.) dunni & 1,00 & 2,63 & 10,97 & 10,48 & & 8,06 & 9,87 \\
\hline Cx. (Mel.) ferreri & 0,28 & 1,26 & 0,00 & 0,00 & & 0,00 & 0,00 \\
\hline Cx. (Mel.) ocossa & 0,96 & 2,57 & 4,42 & 3,20 & & 0,16 & 0,38 \\
\hline Cx. (Mel.) pedroi & 0,04 & 0,27 & 0,12 & 0,33 & & 2,16 & 2,04 \\
\hline Cx. (Mel.) spissipes & 0,02 & 0,14 & 0,00 & 0,00 & & 0,11 & 0,47 \\
\hline Cx. (Mel.) spp. & 8,80 & 14,02 & 25,58 & 23,82 & & 4,89 & 4,85 \\
\hline Culex spp & 2,50 & 4,56 & 5,40 & 16,43 & & 1,22 & 4,11 \\
\hline Cq. (Rhy.) nigricans & 0,17 & 0,72 & 0,18 & 0,40 & & 0,00 & 0,00 \\
\hline Jb. longipes & 0,04 & 0,19 & 0,00 & 0,00 & & 0,56 & 0,24 \\
\hline Ma. (Man.) indubitans & 129,51 & 259,90 & 14,97 & 12,84 & & 2,17 & 5,65 \\
\hline Ps. (Jan.) albipes & 5,17 & 14,15 & 2,36 & 2,52 & & 37,56 & 41,68 \\
\hline Ps. (Gra.) cingulata & 1,99 & 2,83 & 17,30 & 13,69 & & 0,00 & 0,00 \\
\hline Ps. (Gra.) confinnis & 0,5 & 2,25 & 2,36 & 2,57 & & 0,00 & 0,00 \\
\hline Ur. (Ura.) geometrica & 0,91 & 1,39 & 3,60 & 4,45 & & 0,00 & 0,00 \\
\hline Ur. (Ura.) lowii & 5,26 & 8,66 & 12,21 & 13,32 & & 0,00 & 0,00 \\
\hline Uranotaenia spp. & 0,13 & 0,52 & 0,00 & 0,00 & & 0,00 & 0,00 \\
\hline Media total & 171,52 & 292,61 & 114,21 & 68,16 & & 73,94 & 64,51 \\
\hline Riqueza de especies & 35 & & 22 & & & 17 & \\
\hline $\begin{array}{l}\text { Índice de evenness } \\
(0-1) \pm I C 95 \%\end{array}$ & $0,22 \pm 0,01$ & & $0,45 \pm 0,01$ & & & $, 35 \pm 0,16$ & \\
\hline $\begin{array}{l}\text { Índice de diversidad } \\
\text { de especies } \pm \text { IC95\% }\end{array}$ & $7,5 \pm 0,25$ & & $9,9 \pm 2,0$ & & & $95 \pm 1,1$ & \\
\hline
\end{tabular}

Ad: Aedomyia; Ae:Aedes; An: Anopheles; Cq: Coquillettidia; Cx: Culex; Jb: Johnbelkinia; Ny: Nyssorhynchus; Ps: Psorophora; Ur: Uranotaenia; a: número de hembras/trampa/noche; b: número de hembras/trampa/ día; CDC: trampa de luz tipo CDC; DE: desviación estandard, IC; intervalo de confianza del 95\%; n: tamaño de la muestra; TT-17: trampa tipo Trinidad. 
$C x$. serratimarge, $C x$. bastagarius y $C x$. bahiensis. Las tres últimas especies se identificaron por la terminalia del macho; no aparecen en el cuadro 1 porque no fue posible identificar las hembras a nivel de especie por características morfológicas externas. Para el análisis se tuvo en cuenta el grupo de Culex (Mel.) spp., el cual registró la mayor abundancia en extradomicilio-CDC.

En relación con la infestación de las viviendas con mosquitos, Ma. indubitans se encontró en el $96,2 \%(50 / 52)$ de las viviendas muestreadas; la distribución de estos mosquitos fue agregada; 10 casas aportaron el $70 \%$ de los mosquitos recolectados. Las especies con posible importancia epidemiológica en la transmisión del VEEV, registraron los siguientes porcentajes de infestación: Cx. (Mel.) occosa, 30,8\% (16/52); Ps. confinnis, $11,5 \%$, (6/52) y Cx. (Mel.) pedroi, $1,9 \%$ (1/52).

Durante el día en el interior de los dormitorios se encontraron 87 hembras de mosquitos, correspondientes a las siguientes especies: Aedeomyia squamipennis (Lynch Arribalzaga, 1878), Cx. (CX.) spp., Ma. indubitans, Ps. (Gra.) albipes, Ps. (Gra.) cingulata y Johnbelkinia longipes (Fabricius, 1805). La especie más abundante fue $P$ s. albipes $(71,3 \%$, $\mathrm{n}=62)$.

Respecto a las formas inmaduras, se inspeccionaron 970 criaderos artificiales potenciales y criaderos naturales. Para Culex (Culex) spp. fueron positivos tres tanques para almacenamiento de agua y una llanta, y para Ps. confinnis, el canal del lado de la vía y una charca en el patio trasero de una vivienda.

\section{Materiales empleados para la construcción de las viviendas, uso de toldillos e insecticidas}

En la inspección ocular realizada en 52 casas se encontró que la madera era el material más frecuente $(63,4 \%, n=33)$, seguida por el cemento $(17,3 \%, n=9)$ y otros materiales $(15,3 \%, n=8)$. En relación con la abundancia de las hembras de acuerdo con el tipo de material de construcción, aunque en las viviendas construidas en madera se observó una aparente mayor abundancia 216,41 mosquitos por trampa CDC por noche (IC95\% 93,66-339,16; $n=33$ ) comparada con las construidas en cemento 68,4 mosquitos por trampa CDC por noche (IC95\% 30,23-125,36; $n=9$ ) y las construidas en otros materiales 95,11 (IC95\% 24,32-165,90; $n=8$ ), estas diferencias no fueron estadísticamente significativas.

El promedio de personas por vivienda fue 9,8 (IC95\% 7,7-11,8; $n=39$ ) y el de toldillos por vivienda 3,45 (IC95\% 1,61-5,35); en el $28 \%$ de las viviendas, los residentes aplicaron insecticidas de tipo comercial.

\section{Hámster}

Los hámster utilizados como atrayentes en las trampas TT-17 no murieron durante el periodo de observación.

\section{Otras especies de mosquitos con importancia en salud pública}

Se señala también el hallazgo en el intradomicilio de las especies Anopheles (Nyssorhynchus) darlingi (Root, 1926) y Anopheles (Anopheles) puctimacula (Dyar and Knab, 1906), vectores primario y secundario de paludismo, respectivamente. No se encontró Aedes aegypti (Linnaeus, 1762).

\section{Discusión}

Desde el punto de vista epidemiológico en el presente estudio se encontraron los mosquitos Cx. pedroi, Cx. occosa, Cx. spissipes, Ps. confínnis y Ma. indubitans, que podrían tener importancia en la transmisión del subtipo ID del VEEV. Las tres primeras especies pertenecen a la serie Spissipes, del subgénero Melanoconion, que incluye todos los vectores de los subtipos enzoóticos (1). Ps. confinnis es considerado vector de las cepas epizoóticas (subtipo IC) y segundo en importancia después de Ae. taeniorhynchus (1). En los estudios realizados por Morales et al. $(27,28)$, a nivel experimental se logró la infección de este mosquito con el subtipo ID y luego la transmisión a ratones. Además, se ha sugerido que $P$ s. confinnis puede servir de puente entre los ciclos del subtipo ID y subtipo IC del VEEV (29). Ma. indubitans, en conjunto con Ma. titillans, han mostrado ser ligeramente susceptibles a cuatro variantes del subtipo ID en estudios realizados en lquitos (Perú) (30) y Ma. titillans se considera un vector potencial para dispersar o exportar desde los bosques el VEEV enzoótico (31). 
Las especies $C x$. pedroi y $C x$. occosa del subgénero Melanoconion, a pesar de su relativa poca abundancia en el presente estudio, podrían estar comprometidas como vectores. Cx. pedroi fue incriminado como vector principal en el valle medio del río Magdalena (7). En Barrancabermeja se asoció a los casos periurbanos en humanos (Ferro C, Ramírez M, González M, Ahumada ML, Boshell J. Ciclo de transmisión enzoótica del subtipo ID del virus de la encefalitis equina venezolana en la periferia de la ciudad de Barrancabermeja valle medio del río Magdalena. Biomédica 2003;23 (Supl.1):125). Experimentalmente, en el área de lquitos (Perú) se ha demostrado que es un vector competente del subtipo ID (30). Cx. occosa fue incriminado como vector en Panamá (32). En Colombia se asoció con la epidemia de encefalitis equina venezolana que afectó solamente a la población de humanos en la represa de Prado (Tolima) (14). Por otro lado, se ha encontrado que los humanos infectados desarrollan viremia alta $(33,34)$ y hay evidencia de brotes pequeños de encefalitis equina venezolana en ausencia de equinos (35). Esta información sugiere la posibilidad de transmisión del VEEV entre humanos, tanto por $C x$. pedroi como por $C x$. occosa $(7,14,32)$.

En el presente estudio, $C x$. pedroi y $C x$. occosa se encontraron tanto en el intradomicilio-CDC como en el extradomicilio CDC y TT-17. Ambas especies registraron una mayor abundancia en el extradomicilio, cerca de las viviendas, detectada para cada especie con un método diferente de captura; $C x$. pedroi fue más atraído por el roedor de la TT-17 y $C x$. occosa por la CDC. En el intradomicilio-CDC, Cx. occosa registró una abundancia media más alta que $C x$. pedroi, lo que sugiere comportamientos diferentes en cuanto a preferencias alimentarias de las dos especies (cuadro 1) que, combinadas, podrían contribuir a mantener el ciclo de transmisión del virus en el caserío. Así mismo, la presencia de Ps. confinnis y la gran abundancia de Ma. indubitans en el intradomicilio podrían constituir un riesgo de epidemia $(8,29,36)$.

Sin embargo, el contacto de los habitantes con el virus es bajo; por serología, sólo dos de los ocho pacientes febriles examinados registraron anticuerpos (Vera N, Villamizar MC, Sanchez LR, Jaimes LS, Rodríguez JP. Informe preliminar estudio de brote de Encefalitis Equina Venezolana, corregimiento de Chingalé, municipio de Puerto Wilches, departamento de Santander. Instituto Nacional de Salud. Secretaría de Salud de Santander. Mayo de 2005) y en cuanto a personas que desarrollaron la enfermedad sólo se tiene conocimiento del caso de la niña de tres años. Si a esta situación le adicionamos que los hámster expuestos como centinelas en este estudio no se infectaron, se puede intuir que el virus no está utilizando todas las especies de mosquitos que potencialmente podrían desempeñarse como vectores, detectadas en este estudio.

Por lo anterior, se puede asumir que el ciclo epidemiológico del VEEV no tiene lugar en el casco urbano de Chingalé. Posiblemente ocurre en un lugar cercano y Culex (Melanoconion) infectados traen el virus al caserío, en donde algunos mosquitos incursionan a alimentarse, comportamiento que puede presentarse en diferentes épocas del año, especialmente cuando la supervivencia de los mosquitos en su hábitat natural es difícil o debido a patrones de distribución de los vectores (15), de lo cual se conoce muy poco.

Respecto a la especie de mosquito que trae el virus al caserío de Chingalé, aunque los más probables son los vectores enzoóticos naturales, especies de la serie Spissipes, del subgénero Melanoconion, no se descarta que especies que no pertenecen a esta serie puedan estar involucradas en movimientos del virus fuera del bosque (15). Del subgénero Melanoconion, la especie $C x$. pedroipodría ser la más comprometida, teniendo en cuenta que este mosquito fue incriminado como vector primario del subtipo ID en un foco enzoótico de transmisión ubicado en el Magdalena Medio, entre Puerto Berrío y Puerto Boyacá (1), donde esta especie registró una gran abundancia a través del año. Además, este mosquito se ha encontrado en los dormitorios de algunas de las viviendas cercanas al foco de transmisión mencionado (Ferro C. Laboratorio de Entomología, Instituto Nacional de Salud. Datos sin publicar). Lamentablemente, por la situación de orden público, en este estudio no fue posible comprobar qué tan distantes estaban los bosques. 
Según los residentes de Chingalé, éstos no se encontraban muy retirados, circunstancia que permitiría a los mosquitos desplazarse entre el bosque y el caserío. Respecto a $C x$. occosa en los estudios anteriores realizados en la región del Magdalena medio, a pesar de la intensidad del muestreo no se encontró infectado y la abundancia relativa fue baja $(1,15)$.

En cuanto a la influencia del material de construcción de la vivienda en la abundancia de los mosquitos recolectados en el intradomicilio-CDC, no se encontró diferencia, posiblemente por las aberturas que tienen las viviendas, que permiten el libre acceso de los insectos a las mismas en las horas de la noche, atraídos por la luz y el $\mathrm{CO}_{2}$ que expiden los humanos. A su vez, el promedio de habitantes por vivienda fue relativamente alto y se encontró en la indagación que utilizan toldillos e insecticidas comerciales, conseguidos con sus propios recursos; este hecho indicaría que los mosquitos causan molestias durante la noche a los residentes de Chingalé.

Por otro lado, los cambios del medio ambiente ocasionados por la intervención humana, específicamente por la colonización y la deforestación, han cambiado los factores de riesgo de muchas enfermedades, tradicionalmente consideradas como enzoóticas, convirtiendo la vivienda en un factor de riesgo; por lo tanto, no es irreal considerar la posibilidad de que los ciclos enzoóticos del subtipo ID del virus estén en el proceso de domesticación. Esto está acorde con la gran abundancia de Ma. indubitans y la riqueza de especies detectada en el intradomicilio en este estudio. La gran abundancia de Ma. indubitans, al igual que la agresividad de esta especie hacia los humanos al invadir su domicilio, están reportadas desde hace muchos años (36).

Durante el día se encontraron pocos mosquitos en el interior de las viviendas. Aparentemente, la mayoría no estaban reposando en las paredes, entraban y salían de los dormitorios atraídos por los humanos.

En cuanto a las formas inmaduras, el hallazgo de $P$ s. confinnis en uno de los caños del río Magdalena y en una charca en el patio trasero de una casa, sugiere el proceso de adaptación de esta especie con los ambientes modificados por el hombre. En relación con el hallazgo de criaderos de las especies $C x$. pedroi y $C x$. occosa, de acuerdo con lo informado en la literatura, los registros son muy pocos; por lo tanto, no nos sorprendió no encontrar formas inmaduras.

En conclusión, aparentemente el ciclo epidemiológico del virus no tiene lugar en el caserío de Chingalé, sino que ocurre en un lugar cercano y Culex (Melanoconion) spp. infectados traen el virus al caserío, en donde algunos mosquitos incursionan a alimentarse.

Además, el presente estudio permitió detectar que, en la noche, la riqueza de especies de mosquitos en el interior de la vivienda es mayor que en el exterior, como también, el riesgo en el que se encuentran los residentes del lugar por la presencia de $P$ s. confinnis, que puede servir de puente entre los subtipos enzoóticos y epizoóticos y de Ma. indubitans por su abundancia intradomiciliaria tan alta.

\section{Agradecimientos}

Por asistencia técnica en el campo, al señor Marco Fidel Suárez, del Instituto Nacional de Salud, y a los señores Luis Gualdrón, Juan Hormiga y Pedro Mesa Cuevas, de la Secretaría de Salud de Santander.

A la bióloga María Cristina Carrasquilla, del Instituto Nacional de Salud, por su colaboración en el análisis estadístico.

\section{Conflicto de intereses}

Los autores declaramos que no existe conflicto de intereses sobre los resultados presentados en este artículo.

\section{Financiación}

Instituto Nacional de Salud, Universidad de Texas y Secretaría de Salud de Santander.

\section{Referencias}

1. Weaver SC, Ferro C, Barrera R, Boshell J, Navarro JC. Venezuelan equine encephalitis. Annu Rev Entomol. 2004;49:141-74.

2. Weaver S. Recurrent emergence of Venezuelan equine encephalomyelitis. In: Scheld WM, Hughes J, editors. Emerging infections I. Washington, D.C.: ASM Press; 1998. p. $27-42$. 
3. Groot H. The health and economic impact of Venezuelan equine encephalitis (VEE). En: Proceedings of the Workshop-Symposium on Venezuelan equine encephalitis virus. Sci Pub No. 243. Washington, D.C.: PAHO; 1972. p. 7-16.

4. Sudia WD. Arthropod vectors of epidemic Venezuelan equine encephalitis. En: Proceedings of the WorkshopSymposium on Venezuelan equine encephalitis Virus. Sci Pub No. 243. Washington, D.C.: PAHO; 1972. p. 15769.

5. Weaver SC, Anishchenko M, Bowen R, Brault AC, Estrada-Franco JG, Fernandez Z, et al. Genetic determinants of Venezuelan equine encephalitis emergence. Arch Virol Suppl. 2004;18:43-64.

6. Jhonson KM, Shelokov A, Peralta PH, Dammin GJ, Young NA. Recovery of Venezuelan equine encephalomyelitis virus in Panama. A fatal case in man. Am J Trop Med Hyg. 1968;17:432-40.

7. Ferro C, Boshell J, Moncayo AC, González M, Ahumada ML, Kang W, et al. Natural enzootic vectors of Venezuelan equine encephalitis virus, Magdalena Valley, Colombia. Emerg Infect Dis. 2003;9:49-54.

8. Anishchenko M, Bowen RA, Paessler S, Austgen L, Greene IP, Weaver SC. Venezuelan encephalitis emergence mediated by a phylogenetically predicted viral mutation. Proc Natl Acad Sci USA. 2006;103:4994-9.

9. Brault AC, Powers AM, Holmes EC, Woelk CH, Weaver SC. Positively charged amino acid substitutions in the E2 envelope glycoprotein are associated with the emergence of Venezuelan equine encephalitis virus. J Virol. 2002;76:1718-30.

10. Oberste MS, Fraire M, Navarro R, Zepeda C, Zarate ML, Ludwig GV, et al. Association of Venezuelan equine encephalitis virus subtype IE with two equine epizootics in Mexico. Am J Trop Med Hyg. 1998;59:100-7.

11. Walton TE, Alvarez O Jr, Buckwalter RM, Johnson KM. Experimental infection of horses with enzootic and epizootic strains of Venezuelan equine encephalomyelitis virus. J Infect Dis. 1973;128:271-82.

12. Dickerman RW, Cupp EW, Groot H, MoralesAlarcón A, Cura E, Dickerman AW, et al. Actividad del virus de la encefalitis equina venezolana en el norte de Colombia, abril y mayo de 1983. Bol Of Sanit Panam. 1987;103:1-9.

13. Sanmartin C, Trapido H, Barreto P, Lesmes Cl. Isolations of Venezuelan and Eastern Equine Encephalomyelitis viruses from sentinel hamsters exposed in the Pacific lowlands of Colombia. Am J Trop Med Hyg. 1971;20:469-73.

14. Groot H, Morales A, Romero M, Ferro C, Prías E, Vidales $\mathbf{H}$, et al. Estudios de arbovirosis en Colombia en la década de 1970. Biomédica 1996;16:331-44.

15. Barrera R, Ferro C, Navarro JC, Freier J, Liria J, Salas R, et al. Contrasting sylvatic foci of Venezuelan equine encephalitis virus in Northern South America. Am J Trop Med Hyg. 2002;67:324-34.

16. Groot $\mathbf{H}$, Morales A, Vidales $\mathbf{H}$. Virus isolations from forest mosquitoes in San Vicente de Chucurí, Colombia. Am J Trop Med Hyg. 1961;10:397-402.

17. Mesa F, Cárdenas J, Villamil LC. Las encefalitis equinas en la salud pública. Bogotá: Facultad de Medicina Veterinaria y de Zootecnia, Universidad Nacional de Colombia; 2005.

18. Davies JB. A small mosquito trap for use with animal or carbon dioxide baits. Mosq News. 1971;31:441-3.

19. Lumsden WH. A trap for insects biting small vertebrates. Nature. 1958;181:819-20.

20. Service M. Mosquito ecology: Field sampling methods. 2nd ed. London: Chapman \& Hall; 1993. p. 988.

21. Lane J. Neotropical Culicidae. Vol.1 y 2. Sao Paulo: University of Sao Paulo; 1953.

22. Cova-García P.Mosquitos de Venezuela. Tomos 1 y 2. Caracas: Ministerio de Sanidad y Asistencia Social; 1966.

23. Faran ME, Linthicum K. A handbook of the Amazonian species of Anopheles (Nyssorhynchus) (Diptera: Culicidae). Mosq Syst. 1981;13:1-81.

24. Sallum MA, Forattini OP. Revision of the Spissipes section of Culex (Melanoconion) (Diptera: Culicidae). J Am Mosq Control Assoc. 1996;12:517-600.

25. Pecor JE, Mallanpalli VI, Harbach RE, Peyton EI. Catalog and illustrated review of the subgenus Melanoconion of Culex (Diptera: Culicidae). Contrib Am Entomol Inst. 1992;27:1-228.

26. Bulla L. An index of evenness and its associated diversity measure. Oikos. 1994;70:167-71.

27. Morales A, Romero M, Olano VA, Calvache D. Demostración del virus de la encefalitis equina venezolana tipo enzoótico en la hemolinfa de mosquitos Psorophora confinnis infectados por vía oral. Biomédica. 1982;2:111-7.

28. Morales A, Romero M, Olano VA. Transmisión experimental del virus de la encefalitis equina venezolana subgrupo ID tipo enzoótico por Psorophora confinnis a ratones. Biomédica.1983;3:10-4.

29. Ortiz D, Aischenko M, Waver SC. Susceptibility of Psorophora confinnis (Diptera : Culicidae) to infection with epizootic (Subtype IC) and enzootic (Subtype ID) Venezuelan equine encephalitis viruses. J Med Entomol. 2005;42:857-63.

30. Turell MJ, Jones JW, Sardelis MR, Dohm DJ, Coleman RE, Watts DM, et al. Vector competence of Peruvian mosquitoes (Diptera:Culicidae) for epizootic and enzootic strains of Venezuelan equine encephalomyelitis virus. J Med Entomol. 2000;37:835-9. 
31. Mendez W, Liria J, Navarro JC, Garcia, CZ, Freier JE, Salas R, et al. Spatial dispersion of adult mosquitoes (Diptera: Culicidae) in a sylvatic focus of Venezuelan equine encephalitis virus. J Med Entomol. 2001:38:813-21.

32. Galindo P, Grayson MA. Culex (Melanoconion) aikenii: natural vector in Panamá of endemic Venezuelan encephalitis. Science. 1971;172:594-5.

33. Bowen GS, Calisher $\mathbf{C H}$. Virological and serological studies of Venezuelan equine encephalomyelitis in humans. J Clin Microbiol. 1976;4:22-7.
34. Weaver SC, Salas R, Rico-Hesse R, Ludwig GV, Oberste MS, Boshell J, et al. Re-emergence of epidemic Venezuelan equine encephalomyelitis in South America. VEE Study Group. Lancet. 1996;348:436-40.

35. Sanmartin-Barberi C, Groot H, Osorno-Mesa E. Human epidemic in Colombia caused by the Venezuelan equine encephalomyelitis virus. Am J Trop Med Hyg. 1954;3:283-93.

36. Forattini OP. Entomología médica. Vol. 3. Sao Paulo: Editora da Universidade de Sao Paulo; 1965. p. 416. 